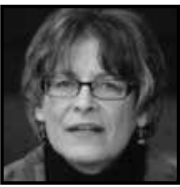

\title{
Commentary
}

\section{Déjà Vu All Over Again: What's Wrong With Hart \& Risley and a "Linguistic Deficit" Framework in Early Childhood Education?}

\author{
Sarah Michaels, Clark University
}

\begin{abstract}
In this invited article, ${ }^{1}$ the author critiques some of the most often-cited scholarship on children's early language development and its relationship to children's learning. She suggests that Hart and Risley's work, Meaningful Differences, adopts an implicit deficit perspective, and makes unwarranted claims about the impact of children's early language on their later thinking and learning abilities. In contrast, she proposes an alternative framework that validates the rich and generative language capacities that children bring with them to school (including poor children, dual-language learners, ethnolinguistic minority children, and children who struggle in school). She argues that using "vocabulary size" or "language deficits" as an explanation for school failure locates school failure in children (with no credible basis) rather than in schools as places where children are failing to, but can, under the right circumstances, learn extraordinarily well.
\end{abstract}

\section{Introduction}

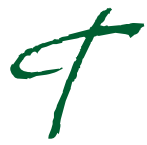

he title of this "commentary" is "Déjà Vu All Over Again," riffing off Curt Dudley-Marling's recent critiques of Ruby Payne's and Hart and Risley's work emphasizing the impact of a "culture of poverty" home environment-on school achievement-which he titles "The Return of the Deficit" as well as on Peggy Miller's critique of the Hart and Risley work entitled, “Déjà Vu: Contesting Language 
Deficiency Again." Both Dudley-Marling and Miller critique the credibility of research that attempts to demonstrate the workings of a linguistic deficits framework in explaining "the achievement gap" or what I think of as school failure. And in a sense, this commentary revolves around the meaning of the term "school failure." Are we talking about the failure of kids in school, or the failure of schools as places where students can learn?

Here I focus on the core inadequacies of the academic scholarship that looks at cultural and linguistic difference and calls it deficiency-using the Hart and Risley work as perhaps the clearest and best example. It's important to examine claims about home environments and the "culture of poverty," especially in light of recent work by sociologists and social justice-oriented scholars who argue that we are wrong to blame schools and teachers alone for the achievement gap; poverty is a huge problem in this society and a huge factor in school failure. So, the critical question is when is a difference just a difference, and when is it a deficit?

Hart and Risley, Meaningful Differences in the Everyday Experience of Young American Children-Google it and in .15 seconds you get over 100,000 hits. Hart and Risley's book Meaningful Differences (1995) is the most-cited piece of academic work that attempts to explain what goes wrong with poor kids, with grand extrapolations and claims (which you'll see that I argue are totally unsubstantiated) about how poor children will fare in school and later life-based on their early home experiences with language. The book purports to demonstrate (with what I will call pseudo-scientific elegance) that poor children (in their study six families, all black, all on welfare) are doomed before they enter school because 1) their parents don't talk to them as much as upper middle class parents (13 upper SES, "professional" families-where the parents were predominantly professors, all white except one); and 2) poor children don't experience as many "quality" features in the talk with their parents.

\section{Coding and Counting Amount of Talk and "Quality" Features}

Their study yielded over 1,000 hours of tape, and in the book, Hart and Risley take great pains to show how meticulously they transcribed and coded the talk, with multiple checks on inter-rater reliability and accuracy, counting how many nouns, verbs, and so forth, and how many new words produced at each visit. But data do not speak for themselves. The quality of data depends on how they are coded and interpreted. 
Hart and Risley coded for six "quality features" they identified (with no explicated basis in any kind of linguistic, psycholinguistic, or cognitive research) as causally linked with children's language learning and cognitive development, their reasoning, ability to learn, and hence, future life chances.

On page 76, they describe how they came up with these "quality features":

We needed to describe more specifically what we saw parents saying and doing that seemed to add quality to everyday interactions. As with our impressions about the stability of a family's style of interacting, we came away from our observations with impressions concerning what made some interactions, in every family, more memorable than others as occasions for teaching and learning. We selected examples of these memorable interactions and used them as a basis for describing the parent behaviors that seemed to make these interactions higher in quality ("better") than others in terms of their developmental importance to language learning. (p. 76, emphasis added)

They arrived at features like "Feedback Tone." Tone denotes the prevailing affect of parent-child interactions, as exemplified by the ratio of affirmative feedback (parent repetitions, expansions, extensions of child utterances), plus words such as "good" and "right" to the total feedback (affirmatives plus prohibitions):

Parent: What's that?

Child: Juice.

Parent: Right, juice. It's orange juice. Good.

This is coded as positive feedback tone because of the repetition, expansion, and affirmation, "good." Sounds like the IRE (Initiation-Response-Evaluation) pattern in school, right? Well, there's increasing evidence that the IRE pattern (teacher initiation, student response, teacher evaluation) does NOT support reasoning, or the development of deep conceptual understanding. It's also culturally specific - the dominant pattern in US schools, but not in other countries, such as Japan.

Another quality feature is Guidance Style (denoting the amount of children's experience with opportunities to choose as exemplified by utterances such as "Can you close the door?" as opposed to directives, like "Close the door."). Any linguist who studies pragmatics will tell you that "Can you close the door?" vs. "Close the door" are formal variants with the same directive function. "Can you close the door?" doesn't offer the 
child any more choice than "Close the door." The difference is in politeness norms and conversational style, and different sub-cultures tend to be more or less direct in their conversational styles.

In fact, all of the so-called "quality" features have to do with politeness and cultural preferences, based on middle class, academic researchers' "impressions" that these features result in higher quality interactions.

There is no research basis for saying that in the case of these differences in conversational style (such as directness over indirectness) that one is cognitively superior. Hart and Risley coded for upper middle class/academic or professional politeness and interactional patterns, found that the upper income families used more of them, and simply asserted that more of the quality features is better in producing learning-related outcomes. They identified upper and middle class features of talk, coded and counted them and found, guess what, they correlate with class.

In short, here's how Hart and Risley go wrong. They code for and count for upper middle class (professional/academic) trappings of language (with no research evidence that these forms of language relate to reasoning, memory, intelligence, or ability to learn). They find huge differences between upper income professional and welfare families, in amount of talk, vocabulary size, and the nature of the talk, in terms of politeness and conversational style. The poor families are all black. The upper SES families are all white except one. Race, ethnicity, and class are hopelessly confounded.

Hart and Risley ignore decades of sociolinguistic and anthropological work on minority and working class speech communities that demonstrates robustly the highly verbal nature of these homes and communities, the documented linguistic richness of these homes. Hart and Risley ignore the work that explores the power of narrative in developing highly abstract and analogical powers of storytelling, reasoning, and argument. They do not code for narrative and they do not code for talk to other adults in the environment, in spite of the fact that work on cultural differences indicates that middle and upper class American families are quite unusual (across the world's cultures) in the degree to which they talk to their infants, and treat them as conversational partners. ${ }^{2}$ 


\section{Hart and Risley Results}

What do they find? Their most robust finding had to do with vocabulary - the high correlation with SES with respect to vocabulary use and vocabulary growth.

This is the study that has generated the often quoted "30-million word gap" between rich and poor children by age four.

The 30-million word gap comes from extrapolating from their six welfare families and 13 upper SES families-based on an hour per month of tape recording in these families, with an observer from the university, over a period of two and half years. Extrapolating from one hour a month and the average number of words heard and spoken (making all sorts of assumptions that would likely not hold, like these hours were representative of every single other waking hour of their lives), they ended up with the 30-million word gap, by the age of four.

The other most significant part of the study is the finding that, more than any other measure, the quality features in parents' talk correlates directly with SES.

The articles I mentioned at the outset by Dudley-Marling and Miller expose numerous methodological problems in the Hart and Risley study. But putting all of these methodological problems aside, even if we accept that Hart and Risley are capturing real differences, we still have to ask are these differences meaningful?

Hart and Risley find that the number of vocabulary words used and heard correlates with results on the Peabody Picture Vocabulary Test (PPVT) and the Stanford Binet IQ test at age three (which Hart and Risley talk about as cognitive "accomplishments" by age three). This is not surprising because the PPVT and Stanford Binet IQ test at age three are in large part vocabulary tests. But there is no evidence that vocabulary size correlates with ability to reason with evidence, interpret others, or think abstractly.

\section{Implications of These Findings?}

Hart and Risley argue the language environment in the home determines the linguistic and cognitive "outcomes" of these children-massively. Here are a few quotes:

"By the time children are 4 years old, intervention programs come too late and can provide too little experience to make up for the past." (p. 2) 
"Differences between families in amount of talk were so persistently characteristic of ongoing family life that they added up to massive differences." (p. 70)

"Skills and knowledge can be improved or retrained; much more intractable are the differences in confidence and motivation gained from years of practice and encouragement in manipulating a vocabulary of symbols and using them to solve problems." (p. 194)

By the way, this last claim is completely unfounded. Hart and Risley didn't assess confidence and motivation, or problem solving - they counted vocabulary, and simply assume or assert that confidence comes from quality features like positive encouragement, and repetition, saying "Juice, right, good" which, again, are just upper middle class forms of talk.

But the take-home message of the Hart and Risley work, bolstered by the "trust me" precision of their charts and graphs, is crystal clear. By the time these low SES kids enter pre-school at four, it's too late. They're broken. They lack confidence (because they missed out on so many middle class-type affirmations and self-esteem boosters), and they lack IQ, and they lack expansive vocabularies, and all of these differences correlate with "cognitive accomplishments" by age three-and simply has to impact these children's educability—that's the precipitous leap of faith for which there is, finally, no evidence. ${ }^{3}$

In addition to claiming cognitive accomplishments due to language by age three, they claim that their findings from the first three years from life explain "intellectual accomplishments" at age nine as well. This is a huge claim, and really the unstated basis for the extensive interest in the book. These differences are claimed to be "meaningful" differences-affecting kids' lives and life chances in school and society beyond the age of three.

They managed to find 29 of the 42 kids at age nine or 10, and gave them a large battery of tests measuring language, $\mathrm{IQ}$, and school performance.

"We were awestruck at how well our measures of accomplishments at 3 predicted measures of language skill at 9-10" (p. 160) (basically, again vocabulary). 
And then Hart and Risley mention-without any real examination-a critically important finding: that these language patterns do NOT relate to educational outcomes (IQ scores or performance on school tasks or tests) in 3rd grade.

This is really the story that should be reported-buried in one paragraph on page 161 and in footnote 6 on page 173 is the following finding:

We saw no association between rate of vocabulary growth and the children's thirdgrade scores in the academic skill areas of reading, writing, spelling, and arithmetic or with scores on the Otis-Lennon School Ability Tests, of verbal and nonverbal reasoning. Nor was there any association seen between either vocabulary use or IQ test score at 3 and performance in these other academic skill areas at 9-10. (p. 161)

We saw no association between children's accomplishments at age 3 (rate of vocabulary growth, vocabulary use, IQ score) and achievement in third grade in academic skill areas other than those specifically related to language. (Footnote 6, p. 173)

No correlation with school or cognitive outcomes...cited widely-over 100,000 citations on Google in .15 seconds.

Cited by very smart, very serious and well-meaning educators, linguists, psychologists, sociologists, politicians and policy makers-glowing about how important this book is. Again and again, one reads, "Hart and Risley's landmark study," "groundbreaking work," "classic investigation."

This is pseudo-science of the worst sort-hidden in what looks like rigorous, highly quantitative definitive results, results offered to guide public policy to promote social justice and equity.

Sadly, their work has generated lots of implications for intervention and public policy-Peggy Miller ends her paper saying, "While putting the final touches on this chapter, we heard a broadcast on National Public Radio ("Closing the Achievement Gap with Baby Talk," January 10, 2011) reporting Hart and Risley's vocabulary findings and describing an intervention program based on these findings. In this program lowincome parents are taught to talk to their babies." Again, I want to remind you that people from different cultures talk differently to infants, and no one approach or style has been shown to be cognitively superior to another in helping children acquire their native language or grow up to be smart. 
In the era of the Common Core, unchallenged research "findings" will spread more easily to every school district in the country. Here is a slide from a videotaped presentation on "Student Engagement \& Future Focus," by Dr. Lisa Leith, available to all through a webinar for the School Improvement Network, posted on the Common Core 360 website:

\begin{tabular}{|c|c|c|c|}
\hline \multicolumn{4}{|c|}{$\begin{array}{l}\text { Research about language in children from } \\
\text { ages } 1 \text { to } 3 \text { years from stable households } \\
\text { by economic group. }\end{array}$} \\
\hline $\begin{array}{l}\text { Number of } \\
\text { words } \\
\text { exposed to }\end{array}$ & $\begin{array}{l}\text { Economic } \\
\text { group }\end{array}$ & $\begin{array}{l}\text { Affirmations } \\
\text { (strokes) }\end{array}$ & $\begin{array}{l}\text { Prohibitions } \\
\text { (discounts) }\end{array}$ \\
\hline $\begin{array}{l}10 \text { million } \\
\text { words }\end{array}$ & Welfare & 1 for every & 2 \\
\hline $\begin{array}{l}20 \text { million } \\
\text { words }\end{array}$ & $\begin{array}{l}\text { Working } \\
\text { class }\end{array}$ & 2 for every & 1 \\
\hline $\begin{array}{l}30 \text { million } \\
\text { words }\end{array}$ & Professional & 5 for every & 1 \\
\hline $\begin{array}{l}\text { Soures. Moaningtul } \\
\text { Sulpety Hart \& Fod }\end{array}$ & $\begin{array}{l}\text { prences in the Everyday } \\
\text { Fistley }\end{array}$ & Feprience of Young Americ & fo Children (1995), \\
\hline
\end{tabular}

Fig. 1: http://www.schoolimprovement.com/pdf/common-core-standards-student-engagement.pdf

This slide promotes Hart and Risley's totally unfounded ideas about conversational style (affirmations vs. prohibitions) as definitive truth, reflected in the "research about language in children," as if the 30-million word gap is common knowledge in the field.

Here's the counterargument: There is no evidence that there's anything wrong with the fundamental linguistic and reasoning skills these kids bring to school. Language is hard-wired in us. These kids get what they need in terms of their linguistic system. They get the grammar and fundamental ability to think with language as a primary cultural tool. They get the ability to learn — to learn language and to learn with language-and 
so whatever they bring from home in terms of discursive repertoires, styles, vocabulary, narrative strategies - they are powerful language and discourse acquirers.

Early language acquisition is not like other social factors-such as nutrition, health care, or environmental toxins. If a kid brings his home grammar and dialect to school, even if that child has a smaller vocabulary than an upper class child, it's not the same kind of difference as the child who brings a toothache or lead poisoning, vs. the child who has had adequate health care. Your primary discourse or home language, or the size of your vocabulary, isn't the same kind of thing as basic nutrition or healthcare.

Every shred of linguistic and linguistic anthropological evidence suggests that the home language kids bring to school is good enough -is all they need as a linguistic and cognitive base to be perfectly good learners. If they engage in subject matter that requires more words, they have no trouble expanding their vocabulary if the words and concepts are meaningful and useful. So when does difference become a deficit?

Doesn't this difference in vocabulary or upper middle class academic conversational style give the wealthy kids an advantage? The answer is complex. Yes, in some respects, and no in others. When poor parents are working three jobs and not around as much to mentor their children, help them with homework, or take them to museums and libraries, their children do not have the same kinds of exposure to and opportunities to learn the kinds of things that are valued in school. While these kids have no fundamental deficit in their language or language learning abilities, they have had less access to academic experiences and conversation. In this regard they start school at a disadvantage. The things that schools value and assess are not the things that these children come to school well practiced in. ${ }^{4}$ On the other hand, it's possible that upper middle class kids get good at spouting big words and concepts, without deep understanding. They get good at sounding smart, but their knowledge is often very superficial (see Michaels, O'Connor, \& Resnick, 2003, for a study of upper middle class and working class fourth graders' reasoning about seasonal change).

But here's the bottom line: Even if kids come to school with an advantage with respect to style or vocabulary, kids are remarkable language and discourse acquirers. There's no evidence that poor kids-immersed in a rich and rigorous, and cognitively demanding school environment, with lots of support to engage in academically productive discussion - can't catch up quickly, and even demonstrate advantages in reasoning power, that come from their early home socialization that emphasizes observation and independent sensemaking (Michaels et al., 2003, Correa-Chávez \& Rogoff, 2009). It's not clear that differences in early home experience with language is cognitively an 
advantage or a disadvantage, but in any case, it's "good enough" so that it doesn't have to make a difference in the long run. Clearly, no one is a native speaker of physics.

\section{Interpreting the "Socializing Potential" of Utterances in Isolation}

Let me give you one example of how easy it is to read deficit into difference, when exploring the impact that home language has on educability. This one comes from the work of Ruqaya Hasan, cited in an article by Gordon Wells - two researchers I might add who are totally committed to research that promotes equity and access in schools.

Sociologists and sociolinguists have long documented differences in the ways that parents engage their young children in dialogue at home, and many have noted the explicit versus implicit nature of information exchange or support for reasoning. Wells (2007) cites the early work of Basil Bernstein (1975) on elaborated versus restricted codes:

[Bernstein] theorized that, although all had access to the same language, adults of different social classes tended to adopt characteristically different ways of using language - different 'orientations to meaning' - according to their involvement in material and symbolic production, either as laborers, directors or creators; these differences would then carry over to the ways in which they talked with their children, thereby differentially preparing the children for the ways in which they would be expected to use language in the context of formal education. (p. 257)

Wells (2007) links these ideas to Hasan's (2002) work on visible versus invisible mediation, which Wells sees as an empirical test of Bernstein's theory:

[Hasan] compared the ways in which Australian middle- and working-class mothers talked with their preschool-aged children in the course of their everyday activities. As Bernstein had predicted, she found systematic differences, which, she suggested, would be consequential in the context of the children's subsequent formal education. To theorize the connection, she proposed a distinction between two modes of semiotic mediation that she observed in her data. The first and most pervasive she termed 'invisible.' This mode of mediation typically occurred on the fly, in the course of some other activity, and the sequences of talk were so brief and apparently insignificant that they hardly merited being called discussions. Yet, as she explained, 
because of their frequency and the different semiotic orientations they may enact, they are critical in establishing what she calls children's 'mental dispositions.' (p. 257)

What are the links between elaborated and restricted codes, visible and invisible mediation, and Wells' notions of monologic and dialogic discourse in the development of knowledge?

Let's take a look at an example of what Hasan (2002) calls "invisible" mediation, characteristic of working class parent/child interactions, and which Wells thinks of as monologic, as opposed to dialogic:

Mother: Put it up on the stove and leave it there.

Karen: Why?

Mother: Cause.

Karen: That's where it goes?

Mother: Yeah. (p. 113)

Wells, in citing Hasan's work, contrasts this with an example of a more expanded dialogue between a mother and a preschooler, one that closely resembles Hasan's (2002) definition of "visible" mediation. In this exchange, a mother and her four-yearold daughter are talking about their neighbors' impending move:

Mother: Did you know that they are going to leave?

Kristy: No.

Mother: They've been building a house.

Kristy: $\quad \mathrm{Mm}$.

Mother: Oh they haven't been building it, somebody else has been building it for them, and it's nearly finished, and they're going to move to their house in May.

Kristy: Why in May?

Mother: They're going to wait until the end of the school term.

Kristy: $\quad$ Mm.

Mother: Because Cathy goes to school now, and then she will change to her new school after the holidays.

Kristy: $\quad \mathrm{Mm}$.

Mother: If they'd moved earlier she'd only go to the new school for a week or two, and then they'd have holidays, you see, it would mess it up a bit for her. (p. 118) 
Wells notes that, while both children ask "why" in these two dialogues, different semiotic orientations are enacted in the way their mothers respond. Examples of this kind are often adduced to suggest stark contrasts between middle-class and workingclass patterns of interaction, reminiscent of Hart and Risley's findings on amount of talk, vocabulary, and parental expansion and elaboration. And while Hart and Risley would talk about vocabulary differences and quality features in the mother's talk, Wells' article characterizes monologic versus dialogic discourse. It makes sense that we would see the first example (where the mother simply says "because" in response to the child's "why?") as an example of a monologic or authoritative or transmission mode, where the child is subtly being told NOT to question or challenge, and is not provided a model of highly explicated reasons. In contrast, the second example looks like a dialogic mode of interaction, where the child's "why questions" receive highly elaborated and explicated answers, and the child is presumably being socialized into a "deliberative" culture, where reflection and questioning and seeking explicated reasons is encouraged.

Why do we automatically "read" these two examples this way? On closer examination, one could argue that the first example is socializing the child to be an independent thinker, a child who is expected to be an active inferencer and reader of others' motives. The mother might be seen as implicitly cuing the child to think and figure things out by herself. She might be saying, "you don't have to be spoon fed; you're smart and alert and can read between the lines." Interestingly, the child responds to the mother's "because" by completing her thought: "That's where it goes?" She is checking with the mother, "Is this what I was supposed to infer? Did I get it right?" The mother indicates that the child got it. One might indeed look at this exchange as a subtle but highly dialogic exchange-where the child is being guided to use others' actions and words as "thinking devices" from which to generate meaning for herself. The exchange is quite implicit in its mode of instruction, and perhaps that is why Hasan calls it "invisible." It does not entail any elaborated explanation "in so many words." But there is evidence of high expectations for reasoning ("you can figure this out"), and evidence of scaffolded support for culturally valued recognition, reflection, and reasoning going on.

In a similar vein, one might well consider the second example (about the neighbors' impending relocation) to be a case of highly monologic information exchange. The child asks the mother "why" and receives something of a lecture. The child takes it (saying "mmm ... mmm"), without any evidence of thinking, challenge, or inferencing. It might well be looked at as socializing a child to "take" authoritative explanations on faith. The mother provides explicit and elaborated reasons, but does not scaffold or encourage the child to reason, to figure things out for herself, or use others' words as a thinking device. This kind of recurring exchange might well prepare a student to take 
information from the teacher or from the textbook and spit back explanations that do not reflect any deeper sense-making ("It's because a vacuum sucked the water up the straw." "It's because of density." "Oh, it's because $y=m x+b$. .).

The deeply destructive, pernicious thing about the Hart and Risley study is that it presents what seems like totally rigorous, careful, objective science (what under careful inspection is nothing more than pseudo-science) - that gives teachers, educators, policy makers the "proof" they need to believe that these poor kids aren't smart, aren't good learners, don't have adequate language to think well with. The very thing that teachers need as a foundation in working productively with these kids-the belief that these kids are capable - and the one thing the work in sociolinguistics and linguistic anthropology has shown definitively - these kids are remarkable language users and learners-is undermined by Hart and Risley. Teachers (and policy makers) are informed that these kids are riddled with deficits, in language, vocabulary, and in their ability to think well and abstractly. That undermines the kind of trusting foundation between teachers and their students that needs to be presumed if it is to be built. So here we have the worst kind of pseudo-science-creating a really pernicious, damaged, and damaging foundation for building intersubjectivity, trusting relationships in schoolsthe view that these kids are deficient in their language and thinking by the time they are four. If you don't presume intelligence, you can't nurture it. This is where difference actually leads to real deficits_-in learning and life chances.

What goes wrong in school with poor children is the building of trust, trusting relationships, built around a rigorous set of learning activities, and the sense that these children are powerful learners-with high quality, cognitively demanding materials and instruction. Here, all of the work on conversational cooperation and intersubjectivity has it right.

To paraphase Ragnar Rommetveit's (1985) famous words: In order to achieve intersubjectivity you have to presume it.

Similarly, in "socializing intelligence" (Lauren Resnick's term), in order help kids get smarter, you have to presume they're intelligent to begin with. In order to open up the conversation to reasoning, you have to believe your kids are good reasoners. 


\section{An Alternative Perspective}

Is there an alternative perspective and are there alternative policy implications? Yes. One only need look at the recent work on "Academically Productive Talk" or "Accountable Talk" (Michaels et al., 2003; Resnick, Michaels, \& O'Connor, in press) describing pedagogical practices that promote language and discourse acquisition, and research on these programs demonstrating robust learning gains and intellectual accomplishments by low SES students, English Language Learners, and students who have traditionally struggled or failed in school.

The work on Accountable Talk (based on extensive linguistic, cognitive, and anthropological research) presumes that kids-all kids-are remarkable language users and learners, and guides teachers-at every grade level-to open up the conversation to student reasoning, building on the linguistic skills the students bring — supporting students to:

- Expand and clarify their own ideas

- Listen carefully to their peers, take them seriously

- Dig deeper into their reasoning with evidence

- Think with others

Even at Pre-K, teachers can be introduced to talk moves and tasks that do this-and once they open up the conversation, you hear teachers say things like, "I had no idea they were so smart." "I never thought HE (he's special ed) had such amazing ideas." In order to promote thinking/ reasoning/ intelligence, you have to presume it.

The really sad thing is that it's not like we don't know better: Research in and out of classrooms has also provided us with principled knowledge about the resources students as language makers and language users bring to the classroom. Regardless of children's race, culture, or socioeconomic status, ALL biologically intact children have well-developed "ways with words" ways of telling stories, giving accounts, providing reasons, abstract arguments, and evidence. This has been robustly documented in the classic research literature on children's language and culture, in the fields of linguistics, sociolinguistics, anthropology, developmental psychology, and cognitive science. (Miller, 1982; Heath, 1983; Taylor, 1983; Gumperz, 1981; Cook-Gumperz, 2006; Gee, 1996; Edwards \& Westgate, 1987; Hymes, 1996; Collins, 2000; Resnick \& Nelson-Le Gal, 1999; Cazden, 2001; Delpit, 1995; Wells, 1993). Linguists have shown-definitively-that all biologically intact children are grammatical speakers of their home language, that is, 
they use language in consistent and rule-governed ways (Labov, 1969; Pinker, 1994). While their dialects may be different from Standard English, all children speak their home dialects as native speakers, with fluency and correctness. Many children even bring a second language to the classroom at a level of sophistication and fluency that few of their teachers can match.

If children have such amazing linguistic abilities, why do we recur to deficits in kids' language to explain school failure? Why does it seem that some students don't bring much, if any, language from home, or don't talk well about academic subjects? These are very common and widespread reactions that teachers have to a culturally and economically diverse group of students. And these are intuitions (based on cultural and linguistic differences) that get reinforced and reified by so-called scientific research leading to claims about vocabulary deficiencies, cognitive disabilities relating to language deficits, and the culture of poverty resulting in language deficits. Hart and Risley's book is just the most highly regarded and cited, with far too little targeted critique from linguists and sociolinguists who know better. ${ }^{5}$ The linguistic deficit work feeds a need for educators to blame something or someone for the children's failures to learn in school. And, sadly, the Hart and Risley work plays into the ideological framework of the social justice-oriented activist researchers who want to blame poverty. But in this case they aren't. They're blaming parents and parents' linguistic and cultural practices-with absolutely no linguistic or cognitive basis for claiming that vocabulary size at age three, or parenting style, whether you use indirect or direct requests, or lots of affirmations or expansions, affects one's confidence, or ability to reason, interpret, or learn.

And yet, this pseudo-science helps teachers blame the parents and the children, but not their own classroom tasks and instructional practices. It also flies in the face of the many, many existence proofs that show that schools with poor children can close the gap and get extraordinary learning to happen. The most damaging message of all in this book, and the language deficit intervention and policy work that makes reference to it, is that it lets the educational establishment off the hook, by colluding in the argument that by age four these kids have irremediable linguistic deficits. Here's what Grover Whitehurst, Assistant Secretary of Education for Research and Improvement, citing Hart and Risley's work, had to say in July 2001: "Children who aren't talked to, who aren't engaged in rich language interaction with their parents, are going to have low levels of vocabulary and conceptual development, and this will affect their later reading and academic achievement."

(http://ies.ed.gov/director/speeches2001/2001_07_26e.asp). 
But we know from every shred of work on intersubjectivity that intelligence is largely social, that in order to promote the development of reasoning and intelligence in action, you have to presume it. You have to believe your kids are smart in order to help them get smarter. The work that pushes language deficits as an explanation for school failure-in the guise of science-does a huge disservice to teachers-not to mention adding insult to injury to children, parents, and the linguistic and cultural resources that are very much intact. It locates school failure in children (with no credible basis) rather than in schools as places where children are failing to, but can, under the right circumstances, learn extraordinarily well.

\section{Notes}

1. This paper was originally presented at AERA (New Orleans, 2011), in an invited symposium on "The Return of the Deficit Framework."

2. The astonishing "erasure" of knowledge emanating from sociolinguistic and anthropological traditions stems from a deep, unexamined methodological hierarchy that treats quantitative work as inherently more valid than ethnographic, qualitative, discourse-analytic work. (I owe this point to Peggy Miller, personal communication.)

3. “Differences between families in amount of talk were so persistently characteristic of ongoing family life that they added up to massive differences. .... In an average 14 hour day, a child spoken to 50 times per hour will hear 700 utterances; a child spoken to 800 times per hour will hear more than 11,000 utterances. ... At the extremes in advantage we saw the consistence and magnitude of the differences in home environments and early experiences we thought separated the daily lives of professors' children and children from impoverished families. Yet, despite those differences, all 42 children learned to talk. All the parents had apparently provided whatever amount of experience was necessary for the children to become effective users of the language" (pp. 70-71, emphasis added). That's when they went looking for what they called "quality features" of interaction.

4. In commenting on Hart and Risley, Jim Gee (personal communication) notes the following: In a society where poor people are working three jobs they simply are not around enough to engage in as much talk as middle class parents. The "quality" of talk issue is a red herring, in my view. When parents talk about their experiences with their children and do not just play 20 questions with them, it is good for the 
kids' school-based language development regardless of the parents' class or any linguistic measures of "quality" or "complexity." H\&R's book is sadly written in a deficit language at times. Their sophistication in linguistics is poor. But their point that interventions where more adults of any social class talk to and work with more kids of any class are helpful is well taken. The same thing is shown in Susan Neuman's library studies (Neuman, 1996, Neuman et al., 2006). The problem the poor kids had was not any deficit in language, it was that no adult was there to mentor them (they were at work), while adults were there to mentor the richer kids. The deficit is in our neo-liberal society, most surely. But that does not mean poor kids are not being cheated. There is also, of course, the problem that what correlates with school success (e.g., Latinate vocabulary) is created by the way we do schooling. That means we either teach kids the correlates or change how schools operate. Decrying the correlations but keeping schools as they can become a "liberal" way to cheat poor children. As for it being "over at 4"-it is only over at 4 or 40 because institutions are built to make that happen. As Shirley Brice Heath said long ago, schools are a good place to practice literacy and other skills, but not to acquire them, in many cases. We live in a society that uses its public school system, by and large, to create service workers, allowing those who can escape to better schools to take the few good jobs at the top.

5. But see Miller \& Sperry (in press) for a helpful critique.

\section{References}

Cazden, C.B. (2001). Classroom discourse: The language of teaching and learning, 2nd edition. Portsmouth, $\mathrm{NH}$ : Heinemann.

Collins, J. (2000). Bernstein, Bourdieu and the new literacy studies. Linguistics and Education, 11(1), 65-78.

Cook-Gumperz, J. (Ed.) (2006). The social construction of literacy, 2nd edition. New York: Cambridge University Press.

Correa-Chávez, M., \& Rogoff, B. (2009). Children's attention to interactions directed to others: Guatemalan Mayan and European-American patterns. Developmental Psychology, 45(3), 630-641.
Delpit, L. (1995) Other people's children: Cultural conflict in the classroom. New York: The New Press.

Edwards, A.D., \& Westgate, D.P.G. (1987). Investigating classroom talk. London: Falmer Press.

Gee. J.P. (1996). Vygotsky and current debates in education: Some dilemmas as afterthoughts to discourse, learning, and schooling. In D. Hicks (Ed.), Discourse, learning and schooling. (pp. 269-282). Cambridge: Cambridge University Press. 
Gumperz, J.J. (1981). Conversational inference and classroom learning. In Ethnography and language in educational settings. J. Green and C. Wallat, (Eds.) (pp. 3-23). Norwood, NJ: Ablex.

Hart, B., \& Risley, T. (1995). Meaningful differences in the everyday experience of young American children. Baltimore: Paul H. Brookes Publishing.

Hasan, R. (2002). Semiotic mediation and mental development in pluralistic societies: Some implications for tomorrow's schooling. In G. Wells \& G. Claxton (Eds.), Learning for life in the 21st century: Socio-cultural perspectives on the future of education (pp. 112-126). Oxford: Blackwell.

Heath, S.B. (1983). Ways with words: Language, life and work in communities and classrooms. Cambridge: Cambridge University Press.

Hymes, D. (1996). Ethnography, linguistics, narrative inequality: Toward an understanding of voice. London: Taylor \& Francis.

Labov, W. (1969). The logic of nonstandard English. Georgetown Monographs on Language and Linguistics, 22, 1-31.

Michaels, S., O'Connor, C., \& Resnick, L. (2003). Accountable talk: Classroom conversation that works. Pittsburgh, PA: University of Pittsburgh.

Miller, P. J. (1982). Amy, Wendy, and Beth: Learning language in South Baltimore. Austin, TX: University Press.

Miller, P.J., \& Sperry, D.E. (in press). Déjà vu: Contesting language deficiency again. Forthcoming in: Fiske, S. \& H. Markus (Eds.). Facing Social Class. New York: Russell Sage Foundation.

Neuman, S. B. (1996). Children engaging in storybook reading: The influence of access to print resources, opportunity and parental interaction. Early Childhood Research Quarterly, 11, 495-513.
Neuman, S.B., \& Celano, D. (2006). The knowledge gap: Effects of leveling the playing field for low- and middle-income children. Reading Research Quarterly, 176-201.

Pinker, S. (1994). The language instinct: How the mind creates language. New York: Harper Perennial.

Resnick, L., \& Nelson-Le Gall, S. (1999). Socializing intelligence. In L. Smith, J. Dockrell, and P. Tomlinson (Eds.), Piaget, Vygotsky and beyond. London: Routledge.

Resnick, L.B., Michaels, S., \& O'Connor, C. (in press). How (well structured) talk builds the mind. In R. Sternberg \& D. Preiss (Eds.), From genes to context: New discoveries about learning from educational research and their applications. New York: Springer

Rommetveit, R. (1985). Language acquisition as increasing linguistic structuring of experience and symbolic behavior control. In J.V. Wertsch (Ed.), Culture, communication, and cognition: Vygotskian perspectives (pp. 183-204). Cambridge, England: Cambridge University Press.

Taylor, D. (1983). Family literacy: Young children learning to read and write. Portsmouth, NY: Heinemann.

Wells, G. (1993). Reevaluating the IRF sequence: A proposal for the articulation of theories of activity and discourse for the analysis of teaching and learning in the classroom. Linguistics and Education, 5, 1-37.

Wells, G. (2007). Semiotic mediation, dialogue and the construction of knowledge. Human Development, 50: 244-274. 


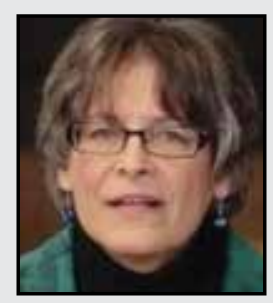

Sarah Michaels is Professor of Education, Chair of the Education Department, and Senior Research Scholar at the Jacob Hiatt Center for Urban Education at Clark University. A sociolinguist by training, she has been actively involved in teaching and research in the area of language, culture, "multiliteracies," the discourses of math and science. She works to bring together teacher education, practitioner research, university-based research on classroom discourse, and state and district-based efforts at educational reform in math, science, and English Language Arts, from Pre-Kindergarten through 12th grade. Michaels has a B.A. from Barnard College and a Ph.D. in Education (Language and Literacy) from UC Berkeley.

LINK TO:

http://www.clarku.edu/faculty/facultybio.cfm?id=15 